\title{
Cyber-attack method and perpetrator prediction using machine learning algorithms
}

\author{
Abdulkadir Bilen ${ }^{\text {Corresp., } 1}$, Ahmet Bedri Özer ${ }^{2}$ \\ ${ }^{1}$ Criminal Department, General Directorate of Security, Ankara, Turkey \\ 2 Department of Computer Engineering, Firat University, Elazığ, Turkey \\ Corresponding Author: Abdulkadir Bilen \\ Email address: abdulkadir.bilen@egm.gov.tr
}

Cyber-attacks have become one of the biggest problems of the world. They cause serious financial damages to countries and people every day. The increase in cyber-attacks also brings along cyber-crime. The key factors in the fight against crime and criminals are identifying the perpetrators of cyber-crime and understanding methods of attack. Detecting and avoiding cyber-attacks are difficult tasks. However, researchers have recently been solving these problems by developing security models and making predictions through artificial intelligence methods. A high number of methods of crime prediction are available in the literature. On the other hand, they suffer from deficiency to predict cyber-crime and cyber-attack methods. This problem is tackled to identify an attack and the perpetrator of such attack, using actual data. The data include the type of crime, gender of perpetrator, damage and methods of attack. The data were acquired from the applications of the persons who were exposed to cyber-attacks to the forensic units. In this paper, we analyze cyber-crimes in two different models with machine-learning methods and predict the effect of the defined features on the detection of cyber-attack method and the perpetrator. We used eight machine-learning methods in our approach and concluded that their accuracy ratios were close. The Support Vector Machine Linear was found out to be the most successful in the cyber-attack method with an accuracy rate of $95.02 \%$. In the first model, we could predict the types of attacks that the victims were likely to be exposed to with a high accuracy. The Logistic Regression was the leading method in detecting attackers with an accuracy rate of $65.42 \%$. In the second model, we predicted whether the perpetrators could be identified by comparing their characteristics. Our results have revealed that the probability of cyber-attack decreases as the education and income level of victim increases. We believe that cyber-crime units will use the proposed model. It will also facilitate the detection of cyber-attacks and make the fight against these attacks easier and more effective. 
4

5

6

7

8

9

10

11

\title{
Cyber-Attack Method and Perpetrator Prediction Using Machine Learning Algorithms
}

\author{
Abdulkadir Bilen ${ }^{1}$, Ahmet Bedri Özer² \\ ${ }^{1}$ Criminal Department, General Directorate of Security, Ankara, Turkey \\ ${ }^{2}$ Department of Computer Engineering, Firat University, Elazığ, Turkey \\ Corresponding Author: \\ Abdulkadir Bilen ${ }^{1}$ \\ Ankara, Turkey \\ Email address: abdulkadir.bilen@egm.gov.tr
}

Abstract - Cyber-attacks have become one of the biggest problems of the world. They cause serious financial damages to countries and people every day. The increase in cyber-attacks also brings along cyber-crime. The key factors in the fight against crime and criminals are identifying the perpetrators of cyber-crime and understanding methods of attack. Detecting and avoiding cyber-attacks are difficult tasks. However, researchers have recently been solving these problems by developing security models and making predictions through artificial intelligence methods. A high number of methods of crime prediction are available in the literature. On the other hand, they suffer from deficiency to predict cyber-crime and cyber-attack methods. This problem is tackled to identify an attack and the perpetrator of such attack, using actual data. The data include the type of crime, gender of perpetrator, damage and methods of attack. The data were acquired from the applications of the persons who were exposed to cyber-attacks to the forensic units. In this paper, we analyze cyber-crimes in two different models with machine-learning methods and predict the effect of the defined features on the detection of cyber-attack method and the perpetrator. We used eight machine-learning methods in our approach and concluded that their accuracy ratios were close. The Support Vector Machine Linear was found out to be the most successful in the cyberattack method with an accuracy rate of $95.02 \%$. In the first model, we could predict the types of attacks that the victims were likely to be exposed to with a high accuracy. The Logistic Regression was the leading method in detecting attackers with an accuracy rate of $65.42 \%$. In the second model, we predicted whether the perpetrators could be identified by comparing their characteristics. Our results have revealed that the probability of cyber-attack decreases as the education and income level of victim increases. We believe that cyber-crime units will use the proposed model. It will also facilitate the detection of cyber-attacks and make the fight against these attacks easier and more effective.

Keywords: Machine-Learning, Cyber-Attacks, Cyber-Crimes, Crime Prediction, Data Analysis, Artificial Intelligence 


\section{INTRODUCTION}

Nowadays, it has become exceedingly difficult to ensure the security of our systems including both corporate and personal data. Major countries, such as the United States and the United Kingdom, struggle with cyber-attacks and crimes by producing various security strategies [1]. Countries are striving to ensure security in cyber space and adapt to this field [2]. Protecting the critical infrastructures has a vital importance for countries. Chemical, financial, health, and energy sectors, even nuclear power plants in some countries can be counted among these [3]. Due to millions of cyber-attacks, financial losses significantly increase day by day [4]. In 2020, data stolen from the information system of Airbus Company were put on the dark web market. Medical data of millions of people have been stolen and even state of emergency has been declared due to attacks on some cities [5]. The most important elements ensuring cyber security are integrity, confidentiality, authentication, authorization, nonrepudiation, and availability [6].

With each passing day, work force becomes insufficient in fighting against cyber incidents and new solutions are sought. Solutions such as autonomous cyber defense systems [7], smart cyber security assistant architecture [8] and intrusion detection systems [9] are investigated in the fight against cyber-attacks and crimes. Researchers use machine-learning methods to detect power outages due to cyber-attacks [10] and to prevent vulnerabilities of the Internet of things [11]. Other areas of use are to determine spam and network attacks [12], to detect the phishing attacks against the banking sector [13] and to reduce sexual crimes on social media [14]. These methods have been implemented in fields as stock prediction [15], risk mapping by crimes [16] and cyber profiling [17]. Predicting crime trend and pattern [18], criminal identity detection [19] and crime prevention [20] are also areas of implementation.

There are three main objectives in our study. First is to use actual cyber-crime data as input to predict a cyber-crime method and compare the accuracy results. Second is to measure whether cyber-crime perpetrators can be predicted based on the available data. The third objective is to understand the effect of victim profiles on cyber-attacks.

In this paper, real cyber-crime data of 5-years in Elazığ / Turkey were used. By using machinelearning methods, the method of attack was predicted, and the perpetrator was detected. The detection was based on features like age, gender, income, education, marital status, occupation, and the damage of the crime. By working on certain features such as age, gender, etc., we predicted the kind of attack methods and the victims of these attacks. These results will be used in cybercrime modelling and attack detection by the police forces dealing with cyber-crimes. Major contributions of the proposed approach are:

- Providing advantages to cyber-crime department as it allows using actual data,

- Enabling prediction of attacks that victims may be exposed to,

- Allowing determination of the optimum performance by comparing machine-learning algorithms.

In Section II, the literature is reviewed, and the current studies and the missing parts are revealed. Section III explains the machine-learning methods to be used in research. Section IV presents the predictions and accuracy rate from the dataset and a comparison with previous studies. Section V includes results and future work. 


\section{RELATED WORKS}

82

83

84

85

86

87

88

89

90

91

92

93

94

95

96

97

98

99

100

101

102

103

104

105

106

107

108

109

110

111

112

113

114

115

116

117

118

119

120

121

122

123

124

The importance of the fight against such cyber-attacks, cyber-crimes and cyber security is highlighted in various studies. Cyber security is the protection of physical-digital data, networks, and technological systems from cyber-attacks, unauthorized accesses, disruptions, modifications, destructions, and damages through various processes, applications, and applied technologies [21]. Cyber-attacks such as distributed denial of service attacks by sending malicious packets [22], phishing attacks to banking and shopping sites that deceive the user [23] have increased significantly. In addition, attackers have been using malicious attack software (virus, worms, trojans, spyware and ransomware) that is installed into the user's computer without any consent of the user [24] increasingly. Again, the most common of these attacks and one of the attacks that are most difficult to be prevented is the social engineering attacks. They are based on technical skill, cunning and persuasion, made by taking advantage of the weakness of the victim. Kevin Mitnick, one of the world's famous hackers in social engineering attacks, penetrated most systems he attacked with this method [25]. In the work by Breda F et al., this attack is mentioned as one of the biggest security vulnerabilities in the system no matter how secure a technical system is [26]. Likewise, attacks against IoT devices, which have increased rapidly in recent years, affect the society considerably. Thus, attacks and threats to the IoT structure should be understood for security purposes [27]. Studies conducted to understand and combat cyber-attacks reveal the importance of crime prediction as discussed in this study.

The attacks described above are defined as prohibited criminal acts within the legal framework of many governments. The duty of fighting against crime and criminals is given to law enforcement departments. Researchers assist the institutions conducting the investigation with various analysis and prediction methods. For example, big data [28] and machine-learning [20] methods have been used to analyze crimes in many studies. They have contributed to crime and crime fighting institutions with artificial intelligence models. Among these are determining the areas where the crime can be committed and its story [29], predicting the crime using spatial, temporal and demographic data [30], and analyzing crime with literacy, unemployment and development index data [31].

Time series of crime data in San Francisco, Chicago and Philadelphia were used for predicting crimes in the following years. Decision Tree classification model performed better than KNN and Naive Bayes [32]. Crime data were passed through two different data processing procedures in Canada. A crime prediction was made with an accuracy between $39 \%$ and $44 \%$ using the KNN and Decision Trees [33]. Data such as location, type, date, time, latitude, and longitude of the crimes taking place in the USA were used as input. The result of the crime predictions made with KNN Classification, Logistic Regression, Decision Trees, Random Forest, Support Vector Machine, and Bayesian methods was that the KNN classification was the most successful with an accuracy of $78.9 \%$ [34].

Thirty-nine different categories of crime data happened in the city of San Francisco were used. By using Gradient Boosted Trees and Support Vector Machines, a model dividing crimes into two classes, blue/white collar crime and violent/non-violent crime, was created. High accuracy was achieved in the classification of blue- \& white-collar crimes. However, the study did not yield significant results in the classification of violent $\&$ non-violent crimes [35]. Data from a 10-year murder occurred in Brazil were used. Predictions with $97 \%$ accuracy were made using the random forest method in order to measure the effect of non-Gaussian residuals and urban metrics on 
125

126

127

128

129

130

131

132

133

134

135

136

137

138

139

140

141

142

143

144

145

146

147

148

149

150

151

152

153

154

155

156

157

158

159

160

161

162

163

164

165 murders. The results of this study revealed that unemployment and ignorance were important variables in murder. Also, the order of importance in predicting the crime was determined [36]. In another study, the type, time and location of the crime data were used to predict crime in certain regions in India. The KNN prediction method was used. The method predicted when and where robbery, gambling, accident, violence, murder, and kidnapping crimes would occur. It was found to be more successful than a similar study conducted previously [37].

Big data and machine-learning framework were implemented by using crime data collected from social media platforms. The data were gathered through Volunteered Geographic Information, web, and mobile crime reporting applications. Crime predictions were produced from the collected data using the Naive Bayes algorithm. The purpose of these predictions is to determine the location of possible crimes and prevent them [38]. The demographic and geographical data of the events that took place in the previous years were used to predict the terrorist incidents in India. This model predicted terrorist incidents using artificial intelligence algorithms and achieved results with relatively high accuracy [39].

The cyber-crime data analyzed were publicly available data from social media platforms, including Facebook and Twitter. Researcher compared the algorithms according to the F-measure value, which is the degree of accuracy and precision. With an accuracy of $80 \%$, RF algorithm was found the best fit in the scenario. Threats were automatically determined through the model analyzing cyber-crimes [40]. Real-time crime data published in the internet news were used through the screening program. SVM, Multinomial NB and RF classification methods were used. The data were separated into two; crime and non-crime. The most important part is that it currently provides analysis to the news [41]. Cyber-crime incident data occurring in India were classified using machine-learning techniques. The model, which predicted crimes with $99 \%$ of accuracy, reduced amount of time spent in analysis and manual reporting [42]. A universally compared intrusion detection dataset obtained from Kaggle was used. DNN was used to develop an effective and efficient intrusion detection system in the IoMT environment to classify and predict unforeseen cyber-attacks. DNN outperformed machine-learning algorithms [43]. When the related works are examined, a summary is presented in Table 1.

Based on the review of the literature, we can suggest that cyber-attacks and crimes are important to study since they cause substantial damages to individuals and states. As we could observe the fields where machine-learning methods were used and these methods were successful in predictions, they were used in our study. Studies made significant contributions to the literature and particularly to the criminal units conducting investigations. In these studies, general crimes, cyber-crimes and attacks are generally used as a dataset. The actual dataset based on personal attributes is studied to a lower extent and therefore a machine learning-based model using the dataset of our study is proposed. Cyber-attack and perpetrator estimation method is tackled due to the importance of fields that are studied. 
When people become a victim of a crime, they resort to cops dealing with that particular type of crime. These data are recorded in detail in the database of this unit. Police units report these crimes by their type, method, year, etc. They prepare statistics according to their characteristics, analyze, and visualize them. When multiple cyber-attacks are made simultaneously against a victim, this is recorded in police records as a single attack. Therefore, it is necessary to look at the details of the event, rather than the statistical data, in order to understand whether multiple methods are used. Although a large number of crimes exist in the database, the focus is cyber-crimes as in recent years. Cyber-crimes have caused considerable material and moral damages and they have not been prevented yet. Cyber-crime is chosen as the subject matter since most studies on this field do not

\section{B. Preprocessing} future crimes based on the characteristics of the victim. In addition, it will provide advantages to the police department in predicting cyber-crimes, profiling these crimes, perpetrators and victims. In addition, thanks to the model, consequential suffering will be prevented. The outcome of the study will enable to take tailored measures and facilitate informing people of the crimes they may be exposed to. Our dataset was real cyber-crime data that occurred in the province of Elazığ between 2015 and 2019. Accessing to actual data and preparing these data for processing with machine-learning methods was a challenging process. When the dataset was obtained, all cybercrime details were examined. The redundant areas were removed using various data science methods. The number of crimes, damages, attacks and methods of attack in the dataset are shown in Figure 1. In addition, the details of these four features are divided into color groups. With these data, predictions were made using various libraries in the Python 3.7 program. Main libraries of this program such as Numpy, Pandas, Matplotlib were used and the data were visualized through this program. The key advantages of using machine-learning methods in the paper are; the possibility to recognize multiple structured and unstructured data patterns, high-level success in detecting crime tactics as they change, extraction of relationships between complex data and the ability to produce results unpredictable by humans.

\section{A. Features}

Feature selection is the process of selecting interrelated and useful features in the dataset. It saves time and memory during data training in machine learning. If the features are improperly selected, time required for training may increase. This makes interpretation of the model difficult and increases the error rate in the model. The attributes of the features in our dataset were determined. Each entry was related to a real crime shown in Table 2. These features were used as inputs in training data. In Figure 2, the criteria of the features in our dataset are determined as median, maximum, and minimum.

Standardization is the rescaling of features in a normal distribution. This needs to be completed before using machine-learning methods. The data were made suitable, numbers from 1 to 10 were 
208

209

210

211

212

213

214

215

216

217

218

219

220

221

222

223

224

225

226

227

228

229

230

231

232

233

234

235

236

237

238

239

240

241

242

243

given according to the variety of data in the columns. The StandardScaler () in the Python library was used to optimize the data to be used in algorithms. The bidirectional relationship between type of crime and damages, attack and method of attack is shown in Figure 3. The data were divided into $80 \%$ training data and $20 \%$ test data.

In the first model, the method of attack was tried to be predicted by giving the features of crime, gender, age, job, income, marital status, education, attack, harm, and perpetrator.

In the second model, the perpetrator of crime was tried to be predicted by giving the features of crime, gender, age, income, job, marital status, education, attack, harm, and attack method.

\section{Logistic Regression (LR)}

It is an equation allowing one to predict the value of one from the other, based on the relationship between two or more variables. Assuming that the variance of $y$ is constant, the coefficients can be solved using the least squares method. This minimizes the error between the actual data point and the regression line. The equation for the Logistic Regression line is given as:

$$
\mathrm{y}^{\prime}=\mathrm{b}+w_{1} x_{1}+w_{1} x_{1}+. .+w_{n} x_{n}
$$

Where,

$\mathrm{y}^{\prime}$ is the desired output,

$\mathrm{b}$ is bias value,

$\mathrm{x}$ is the property of the input,

$\mathrm{w}$ is the weight of the features.

\section{K-Nearest Neighbors (K-NN)}

The KNN classifier is based on the distance function that measures the difference and similarity between two or more samples. The Euclidean distance $\mathrm{d}(\mathrm{x}, \mathrm{y})$ between two samples is defined as:

$$
\mathrm{d}(\mathrm{x}, \mathrm{y})=\sum_{k=1}^{n}\left(x_{k}+y_{k}\right)^{2}
$$

Where, $x_{k}$ and $y_{k}$ are the $n^{\text {th }}$ element. $\mathrm{n}$ is the $n^{\text {th }}$ property of the dataset.

First, the $\mathrm{k}$ parameter is determined and the distance of the new data to be included in the dataset is calculated one by one according to the existing data. The closest neighbour is found and assigned to the neighbour class $\mathrm{k}$.

\section{E. Support Vector Machine (SVM)}

This method includes support vector classification and support vector regression. SVM is based on the concept of decision limits, supporting both binary and more classifications. Considering the training data $\mathrm{D}$ :

$$
\mathrm{D}=\left\{\left(x_{i}, y_{i}\right) \mid x_{i} \in \mathrm{R} \mathrm{p}, y_{i} \in\{-1,1\}\right\}_{i=1}^{n}
$$


244

245

246

247

248

249

250

251

252

253

254

255

256

257

258

259

260

261

262

263

264

265

266

267

268

269

270

271

272

273

274

275

276

277

278

Here $y_{i}$ is 1 or -1 and determines the class to which the $x_{i}$ point belongs. Every $x_{i}$ is a pdimensional real vector. The support vector is at the closest point to the hyperplane of optimum separation. In the classification process, mapping input vectors on the separation hyperplane side of the feature space fall into one class, and locations fall into the class on the other side of the plane.

\section{F. Naive Bayes (NB)}

The naive bayes classifier is a simple probability classifier based on applying Bayes' theorem with strong independence assumptions between properties. A naive bayes based on the multi-label classification model can be applied. Given a dataset $\left\{a_{1}, a_{2}, \ldots, a_{j}\right\}$ labelled $\left\{v_{1}, v_{2}, \ldots, v_{j}\right\}$, the results are predicted using the following equation:

$$
v_{N B}={ }_{v_{j} \in \mathrm{V}}^{\arg \max } P\left(v_{j}\right) \prod_{i} P a_{i} \mid v_{j}
$$

\section{G. Decision Tree (DT)}

Decision tree is a classification method that creates a tree-like model consisting of decision nodes and leaf nodes by classification, feature, and target. A decision tree or classification tree is a tree where each internal node is labelled with an input property. Arcs from this tagged node are tagged with each of the possible values of the target attribute or lead to a sub-decision node in a different input attribute. A tree can learn by dividing the set of resources into subsets according to an attribute value test. This process is repeated in a recursive manner, called recursive partitioning, on each derived subset. The iteration is complete when the subset in a node has the full value of the target variable or the division no longer adds value to the predictions.

$$
(\mathrm{x}, \mathrm{Y})=\left(x_{1}, x_{2}, x_{3}, \ldots, x_{k}, \mathrm{Y}\right)
$$

The dependent variable $\mathrm{Y}$ is the target variable that we are trying to understand, classify or generalize. The vector $\mathrm{x}$ consists of input variables such as $x_{1}, x_{2}, x_{3}$ used for this task.

\section{H. Random Forest (RF)}

Random forest is an algorithm that creates classifier on training data and combines outputs to make the best predictions on test data. Randomness minimizes variance to avoid over-learning according to training data.

$$
y=\underset{\mathrm{p} \in\left\{h\left(x_{1}\right) . h\left(x_{k}\right)\right\}}{\operatorname{argmax}}\left\{\sum_{j=1}^{k}\left(\mathrm{I}\left(\mathrm{h}\left(\mathrm{x} \mid \theta_{j}\right)=p\right)\right)\right\}
$$

Where,

$\mathrm{h}(\mathrm{x} \mid \theta)$ is a classification tree,

$\mathrm{k}$ is the number of the tree selected from a pattern random vector.

If $\mathrm{D}(\mathrm{x}, \mathrm{y})$ represents the training data, each classification tree in the ensemble is constructed using a different subset $\left.D_{\theta_{k}}(x, y) \subset D(x, y)\right)$ of the training data. Each tree then works like normal decision trees. Data is segmented by randomly selected value until it is fully partitioned, or the maximum allowed depth is reached. 
279

280

281

282

283

284

285

286

287

288

289

290

291

292

293

294

295

296

297

298

299

300

301

302

303

304

305

306

307

308

309

310

311

312

313

314

315

\section{I. eXtreme Gradient Boosting (XGBoost)}

The first step in XGBoost is to make the first prediction (base score). This prediction can be any number, as the correct result will be reached by converging with the operations to be done in the next steps. This number is 0.5 by default.

First, the loss function $\mathrm{L}\left(y_{i}, \mathrm{~F}(\mathrm{x})\right)$ is created. $y_{i}$ is the observed value, $\mathrm{F}(\mathrm{x})$ is the predicted value:

$$
F_{0}(x)=\underset{\gamma}{\operatorname{argmin}} \sum_{i=1}^{n}\left(\mathrm{~L}\left(y_{i}, \gamma\right)\right.
$$

Here, the constant variable is determined. It is the value loss function in sigma in the formula. $\gamma$ (gamma) is the predicted value.

$$
r_{i m}=-\left[\frac{\partial L\left(y_{i}, \mathrm{~F}\left(x_{i}\right)\right)}{\partial \mathrm{F}\left(x_{i}\right)}\right] \mathrm{F}(\mathrm{x})=F_{m-1}(x) \quad \mathrm{i}=1, \ldots, \mathrm{n}
$$

Where,

r means residual,

$\mathrm{i}$ is observation number, $\mathrm{m}$ denotes the number of the established tree.

The basic learning terminal node in tree growth is the regression tree. It is formulated below:

$$
\begin{gathered}
\gamma_{i m}=\underset{\gamma}{\operatorname{argmin}} \sum_{x_{i} \in R_{i j}} \mathrm{~L}\left(y_{i}, F_{m-1}\left(x_{i}\right)+\gamma\right) \quad \mathrm{j}=1 \ldots \mathrm{J}_{m} \\
F_{m}(x)=F_{m-1}(x)+\sum_{j=1}^{j_{m}} \gamma_{j m} I\left(x \in R_{j m}\right)
\end{gathered}
$$

\section{J. Accuracy, Precision, Recall, F1-Score}

Accuracy (Acc) score is a method used to evaluate the performance of the model made by comparing the predictions made after running the algorithm with the test data. A value between 0 and 1 is produced according to the ratio of the entire predicted value for a prediction to match with the real values. To determine the accuracy of the forecast:

- $\quad \mathrm{TP}=$ Prediction is positive(normal) and actual is positive(normal).

- $\quad \mathrm{FP}=$ Prediction is positive(normal) and actual is negative(abnormal).

- $\quad \mathrm{FN}=$ Prediction is negative(abnormal) and actual is positive(normal).

- $\quad \mathrm{TN}=$ Prediction is negative(abnormal) and actual is negative(abnormal)

The other evaluation metrics for the proposed model are precision, recall and F1-score. Precision (P) is the rate of correctly classified positive instances to the total number of positive instances. Recall (R) shows how successfully positive instances are predicted. F1-Score (F1) is the weighted average of the Precision and Recall values.

$$
A c c=\frac{T P+T N}{T P+T N+F P+F N}
$$

1

$$
P=\frac{T P}{T P+F P}
$$

$$
R=\frac{T P}{T P+F N}
$$


The study aims to analyze the data collected about incidents correctly, to avoid crimes and to catch the perpetrators. The main subject of this paper is to draw conclusions from the analyzed data and combat crimes based on the outcome. These results will reveal and shed light on the investigations carried out by law enforcement officers and any concealed facts. Based on the information on the victim and the method of the cyber-crime, and whether the perpetrator is identified or not, machine-learning methods may be used to determine if the same perpetrator carried out the cyber-attack. The damages suffered by the victims in cyber incidents in Elazığ province have been discovered over the years through various methods. The sum of monetary damages suffered by each victim in the dataset was obtained by summing over the years. It is thought that the decrease in such incidents, observed especially after 2017, results from deterrence secured by the laws and awareness activities. The amount of economic losses due to cyber-attacks is profoundly serious in Elazığ, as shown in Figure 4. The damage mentioned above is enough to show the importance of dealing with cyber security and attack methods.

330

331

332

In this section, results obtained by use of Support Vector Machine (Linear), Random Forest, Logistic Regression, eXtreme Gradient Boosting, Support Vector Machine (Kernel), Decision Tree, K-Nearest Neighbors, Naive Bayes algorithms are presented. We can evaluate the Pearson correlation coefficient between these data as shown in Figure 5. This correlation matrix shows that there are substantial correlations between practically all pairs of variables.

During the experiment, the dataset was first trained and tested in all algorithms. Accuracy and evaluation criteria were also adopted. Accuracy, precision, recall and F1 score values were obtained by comparing the predicted values with the test data.

The prediction accuracy, precision, recall and F1-score data among the algorithms of the first model predicting the method of attack are shown in Table 3 . The comparison of accuracy is shown in Figure 6. When the results were compared, SVML showed the best performance with an accuracy rate of $95.02 \%$ in terms of prediction accuracy. SVML algorithm outperformed RF, LR, XGBoost, SVMK, DT, KNN, and NB algorithms by $0.54 \%, 1.1 \%, 1.66 \%, 2.2 \%, 2.76 \%, 5.52 \%$ and $13.25 \%$ margin, respectively. NB showed the poorest performance with a rate of $81.7 \%$. The performances of algorithms other than NB were close to each other. The distribution graph of the actual values and the predicted values obtained by the SVML algorithm are shown in Figure 7a and the error matrix is shown in Figure $7 \mathrm{~b}$.

Comparing the model in terms of precision, recall and F1-scores, the best result was also obtained with SVML algorithm, albeit a small margin. While LR, SVMK, DT, RF and XGBoost gave results above $92 \%$, their performances were close to each other. Out of these three scores, a difference of approximately $10 \%$ was found between the underperforming KNN and NB. In general, all algorithms produced sufficient results. These results showed that the machine-learning approach could be successfully applied to predict the cyber-attack method. In the model to be 
359

360

361

362

363

364

365

366

367

368

369

370

371

372

373

374

375

376

377

378

379

380

381

382

383

384

385

386

387

388

389

390

391

392

393

394

395

396

397

398

399

created, when the features of a person (Table 2) are entered, it can be predicted which crime such person will be exposed to. Also, warning systems can be created for groups of persons.

The prediction accuracy, precision, recall and F1-scores data among the algorithms of the second model that predicts the attacker are given in Table 4. The comparison of accuracy is shown in Figure 8. LR showed the best performance in this model with $65.42 \%$ and SVML, KNN, SVMK, XGBoost, RF, DT and NB algorithms achieved accuracy with a margin of $0.78 \%, 0.85 \%, 1.33 \%$, $1.39 \%, 1.88 \%, 2.44 \%$ and $3.34 \%$, respectively. Even though NB showed the poorest performance, the performances of algorithms were very close to each other. The distribution graph of the actual values and the predicted values obtained by the SVML algorithm are shown in Figure 9a and the error matrix is shown in Figure 9b.

In terms of precision, recall, and F1-scores, the results of the algorithms varied between 55\% and $65 \%$. The results were not satisfactory. Based on the known/unknown feature of the perpetrator, we aimed to find out whether the same perpetrator committed the crime after comparing the features of the attacker who carried out the incident. However, the results of the model indicated that a new model should be created by adding new attributes.

When the papers shown in the table in section II are compared with our model, eight of the datasets of these works include general street-crimes. One of them works with terrorist crimes, and two of them work with cyber-crimes. Cyber-crime data is one of the less studied crime types in the literature so that we use these data for our proposed study.

In the other predictions, it is seen that the data such as the type, time, place, region, attacker, demographic and regional factors of the crime are mostly used as features. In our study, predictions are made according to the features of age, gender, income, occupation, harm, and attack methods because there are very few studies using these features.

When the studies conducted by Arora et al. and Ch et al. were compared with our study, it was found out that some features were similar. All studies focused on cyber-crime, the datasets and parameters were different from each other, though. The accuracy rate was found to be $80 \%$ in the study conducted by Arora et al. and $99.3 \%$ in the study carried out by $\mathrm{Ch}$ et al.

The limitation of our study is the quantity of data set since our data set consists of actual data. The temporal data enables estimation of time series; however, these data are not available in our dataset. Likewise, if the technical details of the attacks were available in the police records, detailed estimates could make it easier to catch the perpetrator.

Many studies have predicted where and when crimes will occur in the future. However, many of them have not touched upon the method by which crimes occur, how they can be prevented, and what the features of the perpetrator are. One of the key advantages of this study is using actual data and it is a preliminary step towards profiling for people having similar features with the attacked victims. Another advantage of the proposed study is predicting what the cyber-attack method will be and whether its perpetrator can be detected. Our results show that any exposure to cyber-crimes reduces as the level of education and income increases.

PeerJ Comput. Sci. reviewing PDF | (CS-2020:10:54129:2:0:NEW 2 Mar 2021) 
400

401

402

403

404

405

406

407

408

409

410

411

412

413

414

415

416

417

418

419

420

421

422

423

424

425

426

427

428

429

430

431

432

433

434

435

436

437

438

439

440

\section{CONCLUSIONS \& FUTURE WORK}

This paper suggests a method that predicts and detects cyber-attacks by using both machinelearning algorithms and the data from previous cyber-crime cases. In the model, the characteristics of the people who may be attacked and which methods of attack they may be exposed to are predicted. It has been observed that machine-learning methods are successful enough. The Support Vector Machines linear method is the most successful of these methods. The success rate of predicting the attacker who will make a cyber-attack in the model is around $60 \%$. Other artificial intelligence methods may be able to try to increase this ratio. In our approach, it is concluded that it is necessary to draw attention to especially malware and social engineering attacks. It is found that the higher the levels of the victim's education and income are, the less the probability of cyberattack is. The primary focus of this study is to lead law enforcement agencies in the fight against cyber-crime and provide faster and more effective solutions in detecting crime and criminals. New training and warning systems can be created for people with similar characteristics by the evaluation of the characteristics of the attack victims emerged in our analysis study.

For future works; crime, criminal, victim profiling, and cyber-attacks can be predicted using deep learning algorithms and the results can be compared. Based on the talks with other authorized units having crime databases, cyber-crime data of other provinces may also be obtained to use for comparison with this study. The data of other provinces can be compared to similar studies. Intelligent criminal-victim detection systems that can be useful to law enforcement agencies in the fight against crime and criminals can be created to reduce crime rates.

\section{REFERENCES}

[1] Reid R, Van Niekerk J. 2014. From information security to cyber security cultures. Information Security for South Africa. IEEE, p. 1-7

[2] Goel S. 2020. National Cyber Security Strategy and the Emergence of Strong Digital Borders. Connections: The Quarterly Journal, 19(1), 73-86 https://doi.org/10.11610/Connections.19.1.07

[3] Critical Infrastructure, https://www.cisa.gov/critical-infrastructure-sectors, Accessed 28 September 2020

[4] Jang-Jaccard J, Nepal S. 2014. A survey of emerging threats in cybersecurity. Journal of Computer and System Sciences, 80(5), 973-993 doi.org/10.1016/j.jcss.2014.02.005

[5] Check Point Security Report. 2020. https://research.checkpoint.com/

[6] Bayuk JL, Healey J, Rohmeyer P, Sachs MH, Schmidt J, Weiss J. 2012. Cyber security policy guidebook (pp. 3-4). Hoboken: Wiley

[7] Crawford J. 2017. The Impact of Artificial Intelligence on Autonomous Cyber Defense. PhD Thesis. Utica College.

[8] Sayan CM. 2017. An intelligent security assistant for cyber security operations. IEEE 2nd International Workshops on Foundations and Applications of Self* Systems (FAS* W). p. 375-376.

PeerJ Comput. Sci. reviewing PDF | (CS-2020:10:54129:2:0:NEW 2 Mar 2021) 
441 [9] Ben-Asher N, Gonzalez C. 2015. Effects of cyber security knowledge on attack detection.

442

443

444

445

446

447

448

449

450

451

452

453

454

455

456

457

458

459

460

461

462

463

464

465

466

467

468

469

470

471

472

473

474

475

476

477

478

479

480 Computers in Human Behavior, 48: 51-61. doi.org/10.1016/j.chb.2015.01.039

[10] Wang D, Wang X, Zhang Y, \& Jin L. 2019. Detection of power grid disturbances and cyberattacks based on machine learning. Journal of Information Security and Applications, 46, 42-52. doi.org/10.1016/j.jisa.2019.02.008

[11] Zolanvari M, Teixeira MA, Gupta L, Khan KM, \& Jain R. 2019. Machine learning-based network vulnerability analysis of industrial Internet of Things. IEEE Internet of Things Journal, 6(4), 6822-6834. doi.org/10.1109/JIOT.2019.2912022

[12] Canbek G, Sagiroglu Ş, Temizel TT. 2018. New techniques in profiling big datasets for machine learning with a concise review of android mobile malware datasets. IBIGDELFT IEEE, p. 117-121.

[13] Moorthy RS, Pabitha P. 2020. Optimal Detection of Phishing Attack using SCA based KNN. Procedia Computer Science, 171: 1716-1725 doi.org/10.1016/j.procs.2020.04.184

[14] Ngejane CH, Mabuza-Hocquet G, Eloff JH, \& Lefophane S. 2018. Mitigating online sexual grooming cybercrime on social media using machine learning: A desktop survey. In 2018 International Conference on Advances in Big Data, Computing and Data Communication Systems (icABCD) pp. 1-6. IEEE.

[15] Gurjar M, Naik P, Mujumdar G, \& Vaidya T. 2018. Stock market prediction using ANN. Int. Res. J. Eng. Technol.(IRJET), 5, 2758-2761.

[16] Wheeler AP, Steenbeek W. 2020. Mapping the risk terrain for crime using machine learning. Journal of Quantitative Criminology, 1-36 doi.org/10.1007/s10940-020-09457-7

[17] Zulfadhilah M, Prayudi Y, Riadi I. 2016. Cyber profiling using log analysis and k-means clustering. International Journal of Advanced Computer Science and Applications, 7.7: 430435

[18] Biswas AA, Basak S. 2019. Forecasting the Trends and Pattems of Crime in Bangladesh using Machine Learning Model. 2nd International Conference on Intelligent Communication and Computational Techniques (ICCT). IEEE, p. 114-118

[19] Bharathi ST, Indrani B, Prabakar MA. 2017. A supervised learning approach for criminal identification using similarity measures and K-Medoids clustering. ICICICT. IEEE, p. 646653

[20] Lin YL, Chen TY, Yu LC. 2017. Using machine learning to assist crime prevention. 6th IIAI International Congress on Advanced Applied Informatics (IIAI-AAI). IEEE, p. 1029-1030

[21] Fischer EA. 2009. Creating a National Framework for Cybersecurity: an Analysis of Issues and Options. Library of congress Washington DC congressional research service

[22] Kaur Chahal J, Bhandari A, Behal S. 2019. Distributed Denial of Service Attacks: A Threat or Challenge. New Review of Information Networking, 24.1: 31-103 doi.org/10.1080/13614576.2019.1611468

[23] Sahingoz OK, Buber E, Demir O, \& Diri B. (2019). Machine learning based phishing detection from URLs. Expert Systems with Applications, 117, 345-357. doi.org/10.1016/j.eswa.2018.09.029 
481 [24] Biju JM, Gopal N, Prakash AJ. 2019. Cyber Attacks and Its Different Types.

482

483

484

485

486

487

488

489

490

491

492

493

494

495

496

497

498

499

500

501

502

503

504

505

506

507

508

509

510

511

512

513

514

515

516

517

518

519

520 doi.org/10.6633/IJNS.201309.15\%285\%29.09

[25] Mitnick KD, \& Simon WL. 2009. The art of intrusion: the real stories behind the exploits of hackers, intruders and deceivers. John Wiley \& Sons

[26] Breda F, Barbosa H, Morais T. 2017. Social engineering and cyber security. International Technology, Education and Development Conference

[27] Kagita MK, Thilakarathne N, Gadekallu TR, Maddikunta PKR, \& Singh S. 2020. A Review on Cyber Crimes on the Internet of Things. arXiv preprint arXiv:2009.05708.)

[28] Rewari S, Singh W. 2017. Systematic review of crime data analytics. International Conference on Power, Control, Signals and Instrumentation Engineering (ICPCSI). IEEE, p. 3042-3045 doi.org/10.1109/ICPCSI.2017.8392284

[29] Hassan M, Rahman MZ. 2017. Crime news analysis: Location and story detection. 20th International Conference of Computer and Information Technology (ICCIT). IEEE, p. 1-6 doi.org/10.1109/ICCITECHN.2017.8281798

[30] Zhao X, Tang J. 2017. Exploring transfer learning for crime prediction. IEEE International Conference on Data Mining Workshops (ICDMW). IEEE, p. 1158-1159 doi.org/10.1109/ICDMW.2017.165

[31] Vineeth KRS, Pandey A, Pradhan T. 2016. A novel approach for intelligent crime pattern discovery and prediction. International conference on advanced communication control and $\begin{array}{llll}\text { computing technologies } & \text { (ICACCCT). IEEE, p. 531-538 }\end{array}$ doi.org/10.1109/ICACCCT.2016.7831697

[32] Feng M, Zheng J, Han Y, Ren J, \& Liu Q. 2018. Big data analytics and mining for crime data analysis, visualization and prediction. In International Conference on Brain Inspired Cognitive Systems (pp. 605-614). Springer, Cham. doi.org/10.1007/978-3-030-00563-4_59

[33] Kim S, Joshi P, Kalsi PS, \& Taheri P. 2018. Crime analysis through machine learning. In 2018 IEEE 9th Annual Information Technology, Electronics and Mobile Communication Conference (IEMCON) (pp. 415-420). IEEE. doi.org/10.1109/IEMCON.2018.8614828

[34] Bharati A, RA Dr S. 2018. Crime Prediction and Analysis Using Machine Learning. International Research Journal of Engineering and Technology (IRJET), 5.09

[35] Chandrasekar A, RAJ AS, Kumar P. 2015. Crime prediction and classification in San Francisco City. URL http://cs229.Stanford.Edu/proj2015/228\{\\}report.Pdf

[36] Alves LGA, Ribeiro HV, Rodrigues FA. 2018. Crime prediction through urban metrics and statistical learning. Physica A: Statistical Mechanics and its Applications, 505: 435-443 doi.org/10.1016/j.physa.2018.03.084

[37] Kumar A, Verma A, Shinde G, Sukhdeve Y, \& Lal N. 2020. Crime Prediction Using KNearest Neighboring Algorithm. In 2020 International Conference on Emerging Trends in Information Technology and Engineering (ic-ETITE) pp. 1-4. IEEE. doi.org/10.1109/icETITE47903.2020.155

[38] Jha P, Jha R, \& Sharma A, 2019. Behavior Analysis and Crime Prediction using, International Journal of Recent Technology and Engineering (IJRTE), p. 1 
521 [39] Verma D, Yarlagadda R, Gartner SS, \& Felmlee D. 2019. Understanding patterns of

522

523

524

525

526

527

528

529

530

531

532

533

534

535

536

537

538 terrorism in india (2007-2017) using artificial intelligence machine learning. The International Journal of Technology, Knowledge, and Society, 15(4), 23-39.

[40] Arora T, Sharma M, Khatri SK. 2019. Detection of Cyber Crime on Social Media using Random Forest Algorithm. 2nd International Conference on Power Energy, Environment and Intelligent Control (PEEIC). IEEE, p. 47-51

[41] Ghankutkar S, Sarkar N, Gajbhiye P, Yadav S, Kalbande D, \& Bakereywala N. 2019. Modelling Machine Learning For Analysing Crime News. In 2019 International Conference on Advances in Computing, Communication and Control (ICAC3) pp. 1-5. IEEE. doi.org/10.1109/ICAC347590.2019.9036769

[42] Ch R, Gadekallu TR, Abidi MH, \& Al-Ahmari A. 2020. Computational system to classify cybercrime offenses using machine learning. Sustainability, 12(10), 4087. doi.org/10.3390/su12104087

[43] RM SP, Maddikunta PKR, Parimala M, Koppu S, Gadekallu TR, Chowdhary CL, \& Alazab M. 2020. An effective feature engineering for DNN using hybrid PCA-GWO for intrusion detection in IoMT architecture. Computer Communications, 160, 139-149. https://doi.org/10.1016/j.comcom.2020.05.048 


\section{Table $\mathbf{1}$ (on next page)}

Table 1. Related work summary comparison 


\begin{tabular}{|c|c|c|c|c|c|c|c|}
\hline Author & Year & Country & Dataset & Features & Method & Accuracy & Advantage \\
\hline $\begin{array}{l}\text { Chandrasekar } \\
\text { at al }\end{array}$ & 2015 & USA & $\begin{array}{l}\text { General Crime in } \\
\text { San Francisco }\end{array}$ & $\begin{array}{l}\text { Date, Day of the } \\
\text { week, Name of the } \\
\text { Police Department } \\
\text { District, Address, } \\
\text { Latitude, Longitude, } \\
\text { Category, } \\
\text { Description, } \\
\text { Resolution }\end{array}$ & $\begin{array}{l}\text { RF, SVM, } \\
\text { Gboost }\end{array}$ & $\begin{array}{l}\text { Md1 SVM } \\
96 \% \\
\text { Md1 } \\
\text { Gboosted } \\
75.02 \%\end{array}$ & $\begin{array}{l}\text { Including time series modeling to } \\
\text { understand temporal correlations of blue } \\
\text { / white collar and Violent / Nonviolent } \\
\text { crime classification data and predicting } \\
\text { fluctuations in different crime categories }\end{array}$ \\
\hline Feng at al & 2018 & USA & $\begin{array}{l}\text { General Crime in } \\
\text { San Francisco, } \\
\text { Chicago, } \\
\text { Philadelphia }\end{array}$ & $\begin{array}{l}\text { Date, Category, } \\
\text { Descript, Dayof } \\
\text { Week, P. D. District, } \\
\text { Resolution, Address, } \\
\text { x, y, Dome, Arrest } \\
\end{array}$ & \begin{tabular}{|l|}
$\mathrm{NB}$, \\
$\mathrm{KNN}, \mathrm{RF}$, \\
$\mathrm{XGBoost}$
\end{tabular} & $\begin{array}{l}\text { XGboost } \\
70 \%\end{array}$ & $\begin{array}{l}\text { Predicting overall crime in the coming } \\
\text { years using time series }\end{array}$ \\
\hline Kim at al & 2018 & Canada & $\begin{array}{l}\text { General Crime in } \\
\text { Vancouver }\end{array}$ & $\begin{array}{l}\text { Crime Type, Month, } \\
\text { Day, Hour, Weekday, } \\
\text { Address, } \\
\text { Neighborhood, x, y }\end{array}$ & $\begin{array}{l}\text { KNN, } \\
\text { XGBoost }\end{array}$ & $\begin{array}{l}\text { Md1 Gboost } \\
41.9 \% \\
\text { Md2 Gboost } \\
43.2 \%\end{array}$ & Predicting crime location \\
\hline Bharati at al & 2018 & USA & $\begin{array}{l}\text { General Crime in } \\
\text { Chicago }\end{array}$ & $\begin{array}{l}\text { Block, Location, } \\
\text { District, Community } \\
\text { Area, Latitude, X, Y, } \\
\text { Longitude, Hour, } \\
\text { Month, }\end{array}$ & $\begin{array}{l}\text { KNN, LR, } \\
\text { DT, RF, } \\
\text { SVM, NB }\end{array}$ & $\begin{array}{l}\text { KNN } \\
78.9 \%\end{array}$ & $\begin{array}{l}\text { Detecting, predicting, and solving crimes } \\
\text { much faster, thereby lowering the crime } \\
\text { rate }\end{array}$ \\
\hline Alves at al & 2018 & Brazil & Murder Crimes & $\begin{array}{l}\text { Child labor, Elderly - } \\
\text { Female- Male } \\
\text { Population, GDP, } \\
\text { Homicides, Income, } \\
\text { Literacy, Sanitation, } \\
\text { Suicides, Traffic } \\
\text { Accidents, } \\
\text { Unemployment }\end{array}$ & RF & RF 97\% & $\begin{array}{l}\text { The prediction revealed that } \\
\text { unemployment and ignorance were the } \\
\text { most important variables in defining } \\
\text { murders in Brazilian cities, and the order } \\
\text { of importance of urban indicators in } \\
\text { predicting crimes was determined. }\end{array}$ \\
\hline Verma at al & 2019 & India & Terrorist Incidents & $\begin{array}{l}\text { Incident Location, } \\
\text { Time, Type, Weapon, } \\
\text { Intensity of Attack, } \\
\text { Capital, Perpetrator }\end{array}$ & $\begin{array}{l}\text { DT, RF, } \\
\text { IG }\end{array}$ & RF $84 \%$ & $\begin{array}{l}\text { Predicting the occurrence of terrorist } \\
\text { incidents on demographic and } \\
\text { geographic data }\end{array}$ \\
\hline Jha at al & 2019 & India & $\begin{array}{l}\text { Murder Crimes on } \\
\text { the Internet }\end{array}$ & $\begin{array}{l}\text { Crime Type, Year, } \\
\text { Address, Place, } \\
\text { Territory }\end{array}$ & NB & NB $51.2 \%$ & $\begin{array}{l}\text { Analyzing crimes in minimum time and } \\
\text { predicting the location and type of future } \\
\text { crimes }\end{array}$ \\
\hline Arora at al & 2019 & Public & $\begin{array}{l}\text { Cybercrime Data } \\
\text { Publicly Available } \\
\text { on Social Media }\end{array}$ & $\begin{array}{l}\text { Synonyms, Age, } \\
\text { Location, Gender, } \\
\text { Hashtags, and } \\
\text { Sarcasm }\end{array}$ & RF & RF $80 \%$ & Detecting cyber threats automatically \\
\hline $\begin{array}{l}\text { Ghankutkar } \\
\text { at al }\end{array}$ & 2019 & Public & $\begin{array}{l}\text { Real-time Crime } \\
\text { Data from HuffPost } \\
\text { News Site }\end{array}$ & $\begin{array}{l}\text { Category, Headline, } \\
\text { Authors, Link, Short } \\
\text { Description, Date }\end{array}$ & $\begin{array}{l}\text { SVM, } \\
\text { MNB, RF }\end{array}$ & RF $85.83 \%$ & $\begin{array}{l}\text { Providing analysis to current news after } \\
\text { being classified as crime and non-crime } \\
\text { data }\end{array}$ \\
\hline Kumar at al & 2020 & India & \begin{tabular}{|l|} 
Murder, \\
Kidnapping, \\
Violence, Robbery, \\
Gambling, \\
Accident, Indore, \\
Crimes
\end{tabular} & $\begin{array}{l}\text { Hour, Longitude, } \\
\text { Latitude, Day of the } \\
\text { Week, Week, Month }\end{array}$ & KNN & \begin{tabular}{|l|} 
Prev \\
$93.23 \%$ \\
Proposed \\
$99.51 \%$ \\
\end{tabular} & $\begin{array}{l}\text { Predicting the type of crime, and where } \\
\text { and when it may occur }\end{array}$ \\
\hline Ch at al & 2020 & India & Cybercrime & $\begin{array}{l}\text { Incident, Harm, } \\
\text { Access, Year, } \\
\text { Violation, Victim, } \\
\text { Offender }\end{array}$ & \begin{tabular}{l|} 
SVML, \\
LR \\
MNB, RF
\end{tabular} & LR $99.3 \%$ & $\begin{array}{l}\text { Finding and analyzing cyber-attacks that } \\
\text { exploit vulnerabilities. }\end{array}$ \\
\hline
\end{tabular}




\section{Table 2 (on next page)}

Table 2. The attributes used for feature selection 


\begin{tabular}{ll}
\hline Crime & $\bullet$ Misuse of Debit Cards or Credit Cards \\
& $\bullet$ Through Informatics Theft \\
& $\bullet$ Hacking into the Information System and Capturing Data \\
\hline Gender & M - F \\
\hline Age & 27 and under / Between 28-37 / Between 38-50 / 51 and above \\
\hline Income & Low - Middle - High \\
\hline Job & Other - Student - Retired - Justice and Security - Health Sector Manager - \\
& Housewife - Education - Technical - Finance Sector \\
\hline Marital status & Single - Married \\
\hline Education & Primary Education - High School - Undergraduate - Graduate \\
\hline Harm & $\bullet$ Internet Shopping by Introducing Himself as a Bank Clerk \\
& $\bullet$ Internet Shopping out of Knowledge \\
& $\bullet$ Withdrawals without Knowledge \\
& $\bullet$ Withdrawing Money by Introducing Himself as a Bank Clerk \\
& $\bullet$ Fraud \\
& $\bullet$ Do Moral Harm \\
& $\bullet$ Threating / Blackmailing \\
& $\bullet$ Obtaining Electronic Bank Accounts \\
& $\bullet$ Copying Bank / ATM Cards \\
& $\bullet$ Hacking Social Media Accounts \\
& $\bullet$ Obtaining and Using Data in Digital Environment \\
& $\bullet$ Selling Counterfeit Products \\
\hline Attack & $\bullet$ Social Engineering \\
& $\bullet$ Hacking Tools or Malware \\
& $\bullet$ Card Copying / Generating Devices \\
& $\bullet$ Phishing Attack \\
& $\bullet$ Receiving Public Data on Social Media \\
& $\bullet$ Creating a Fake Shopping Site \\
\hline Known - Unknown \\
\hline Attack Method & \\
& \\
& \\
& \\
&
\end{tabular}




\section{Table 3 (on next page)}

Table 3. Performance of machine learning algorithms for model 1 


\begin{tabular}{|l|l|l|l|l|}
\hline & Accuracy \% & Precision \% & Recall \% & F1-score \% \\
\hline LR & 93.92 & 94.41 & 93.92 & 94.1 \\
\hline KNN & 89.5 & 71.73 & 76.24 & 72.69 \\
\hline SVML & 95.02 & 95.43 & 95.03 & 95.16 \\
\hline SVMK & 92.82 & 92.99 & 92.82 & 92.88 \\
\hline NB & 81.77 & 81.79 & 81.77 & 81.23 \\
\hline DT & 92.26 & 92.3 & 92.27 & 92.28 \\
\hline RF & 94.48 & 94.48 & 94.48 & 94.48 \\
\hline XGBOOST & 93.36 & 92.75 & 92.82 & 92.76 \\
\hline
\end{tabular}

1 


\section{Table 4 (on next page)}

Table 4. Performance of machine learning algorithms for model 2 


\begin{tabular}{|l|l|l|l|l|}
\hline & Accuracy \% & Precision \% & Recall \% & F1-score \% \\
\hline LR & 65.42 & 60.67 & 60.22 & 59.14 \\
\hline KNN & 64.57 & 56.85 & 56.91 & 56.85 \\
\hline SVML & 64.64 & 65.75 & 64.64 & 63.54 \\
\hline SVMK & 64.09 & 65.24 & 64.09 & 62.90 \\
\hline NB & 62.08 & 57.93 & 57.46 & 55.66 \\
\hline DT & 62.98 & 63.50 & 62.98 & 62.18 \\
\hline RF & 63.54 & 63.91 & 63.54 & 62.92 \\
\hline XGBOOST & 64.03 & 65.74 & 65.19 & 64.55 \\
\hline
\end{tabular}

1 
Figure 1

Figure 1.The number of crimes, damages, attacks and methods of attack in the dataset

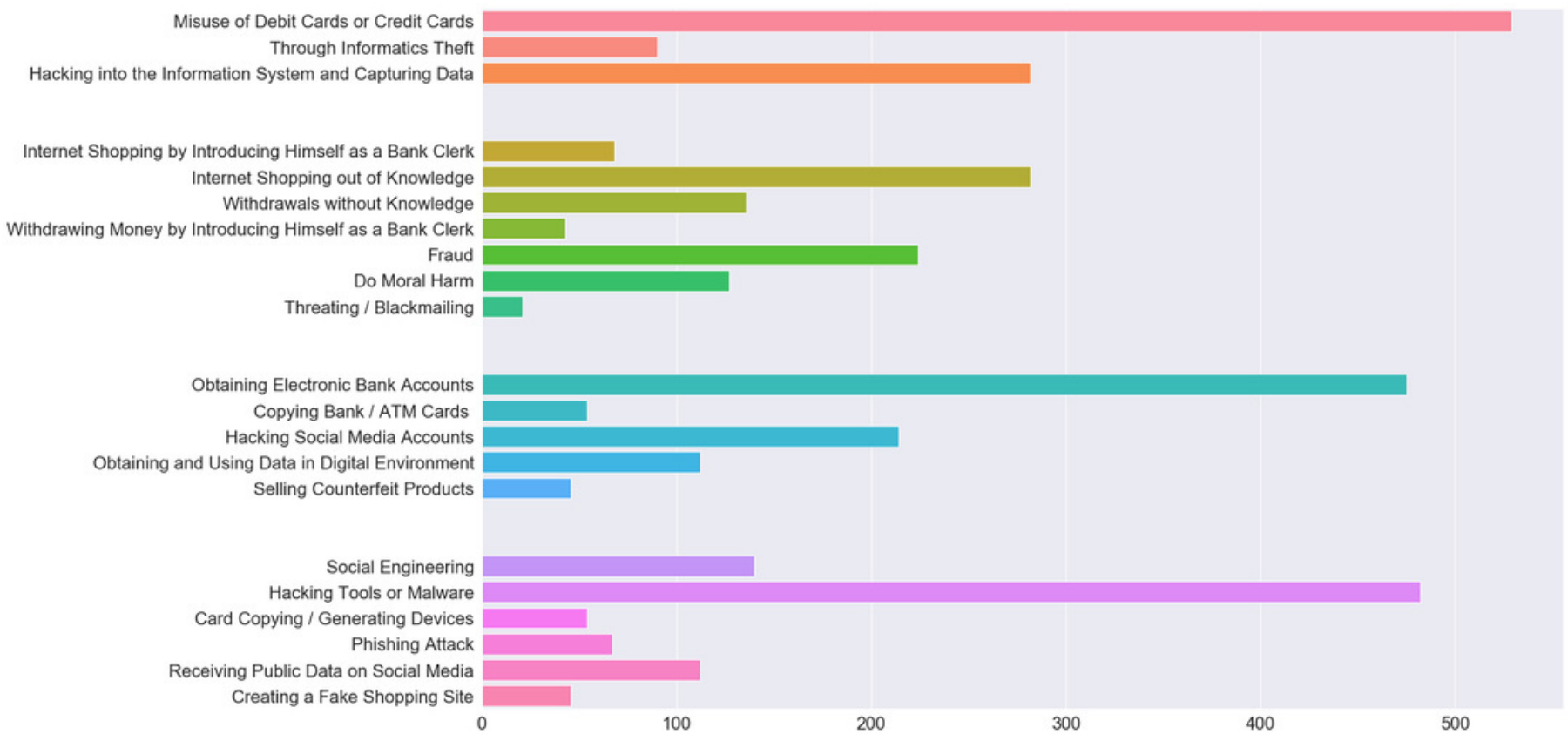


Figure 2

Figure 2. Measure of features

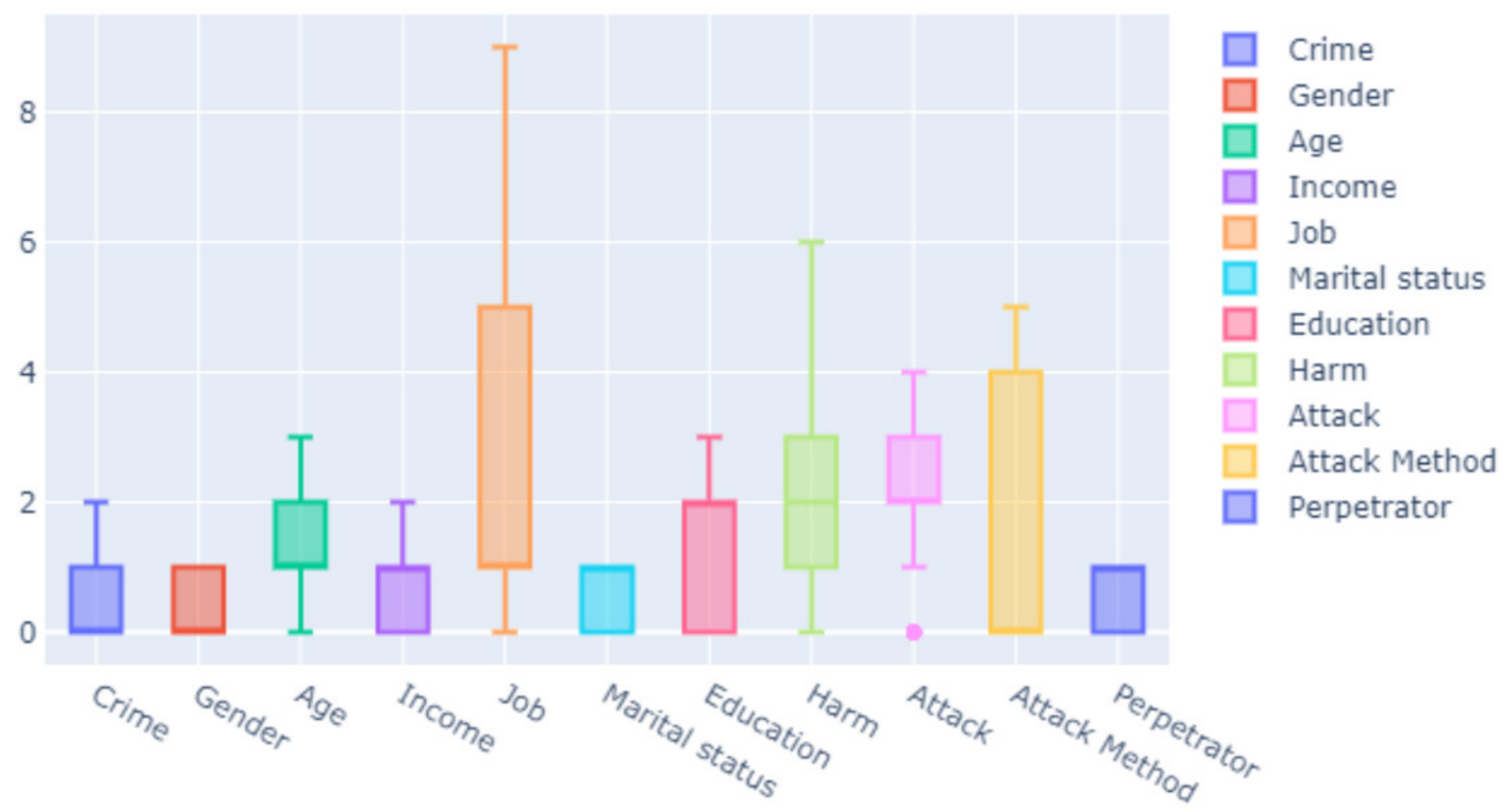


Figure 3

Figure 3. Pairwise relationship between crime, harm, attack, and attack method
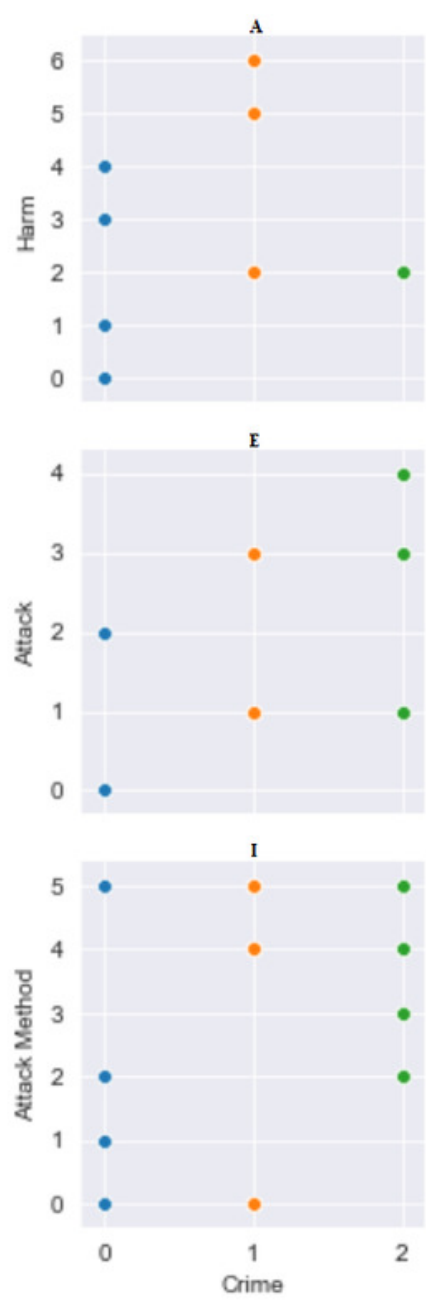

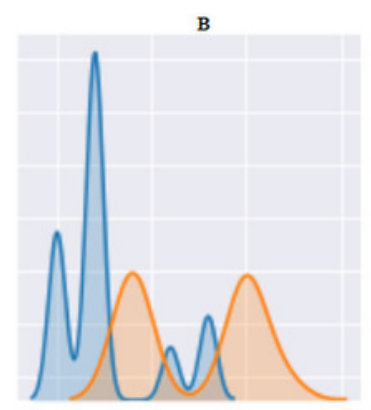

$\mathbf{F}$
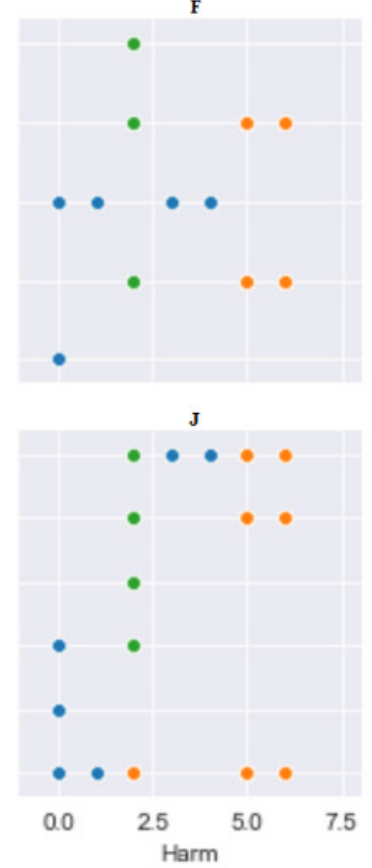
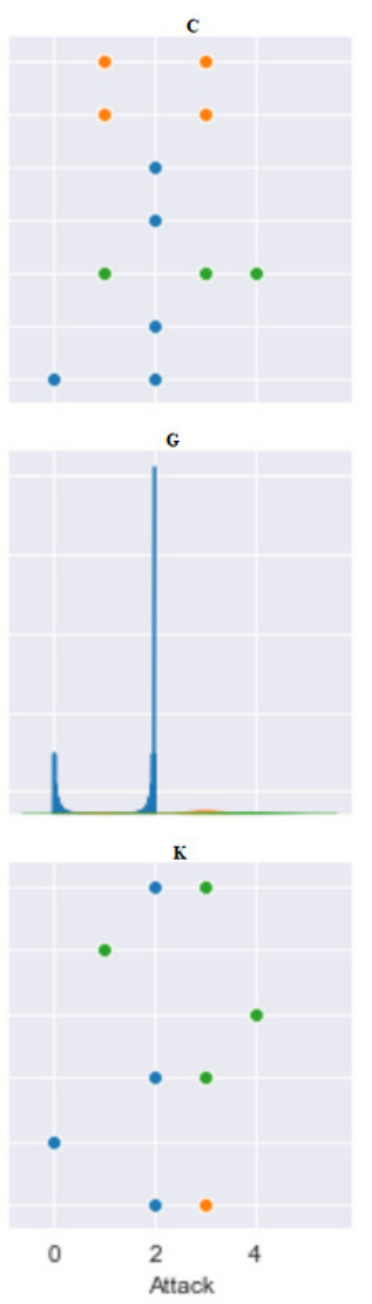
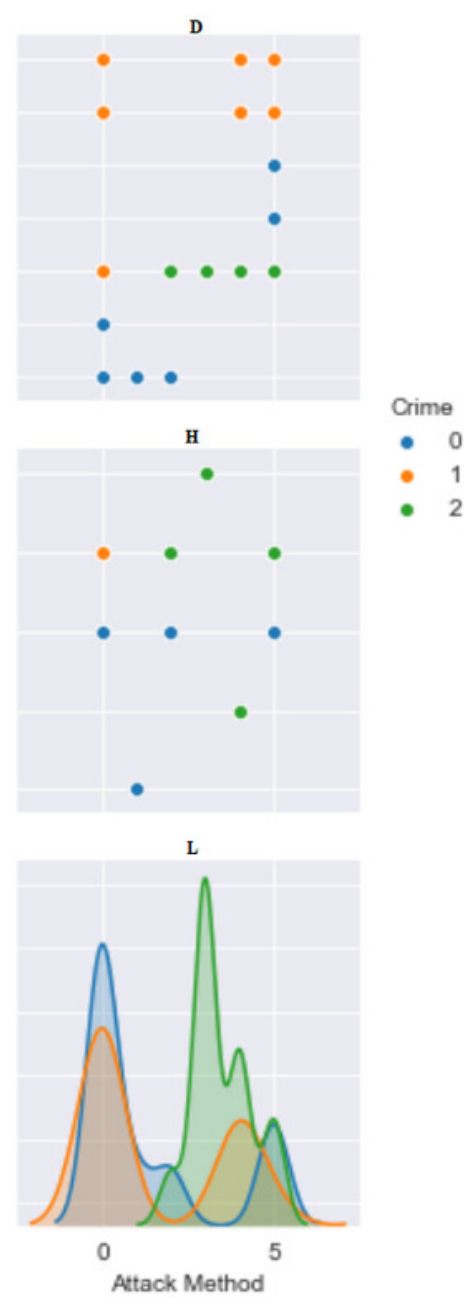
Figure 4

Figure 4. Damage caused by cyber-attacks in Elazığ province

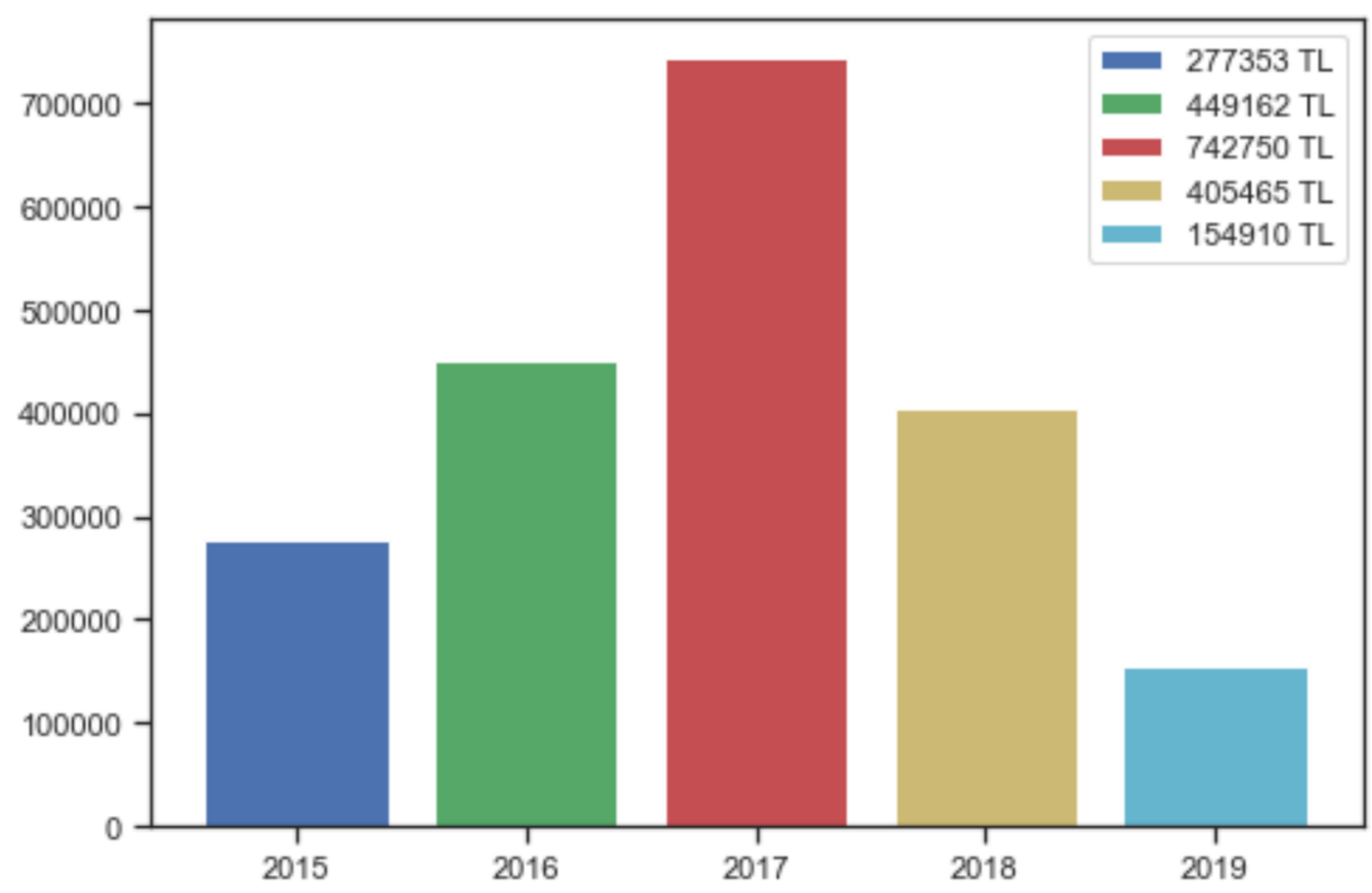




\section{Figure 5}

Figure 5. Pearson's linear correlations matrix

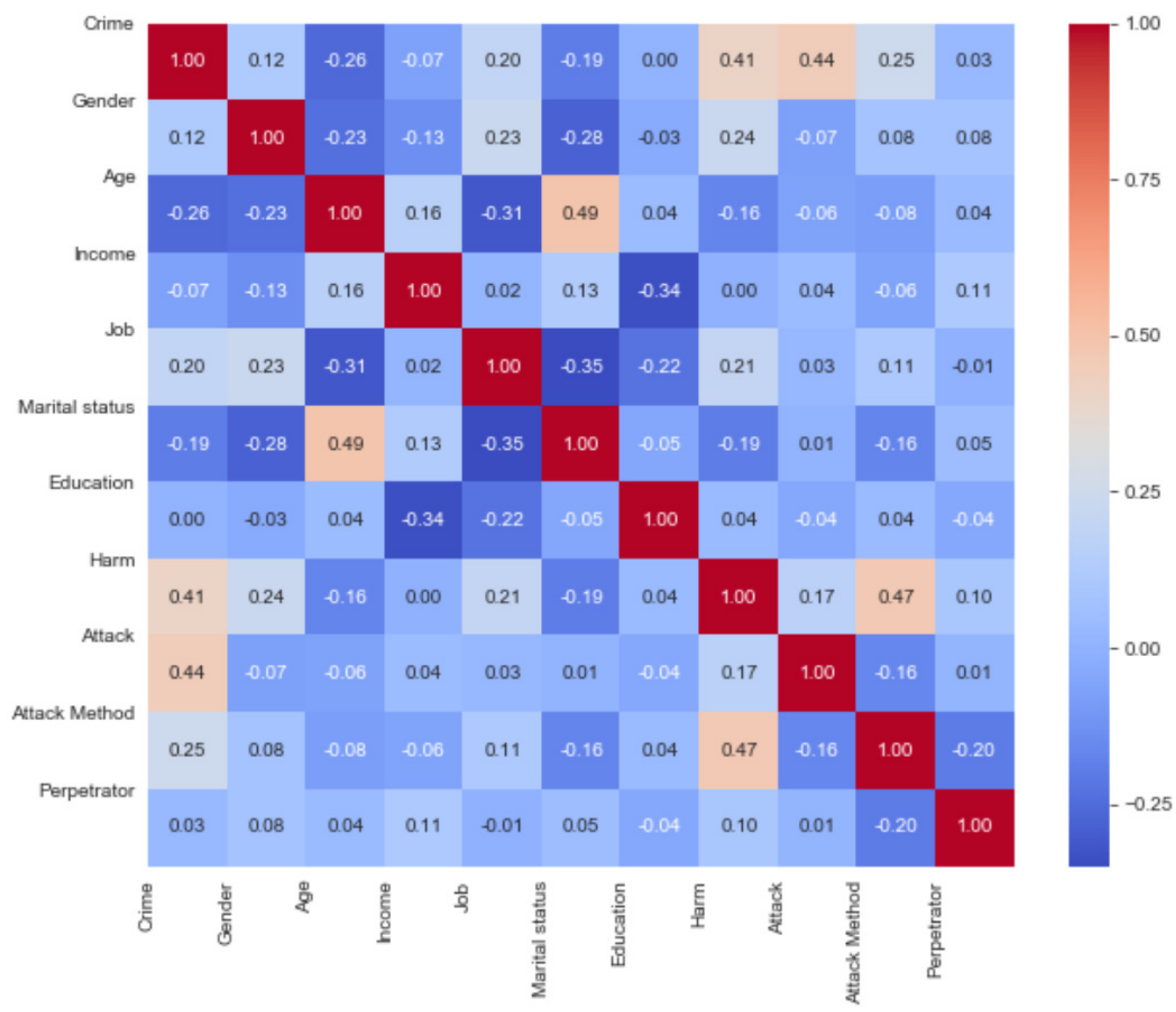


Figure 6

Figure 6. Accuracy rate of algorithms applied in attack method prediction

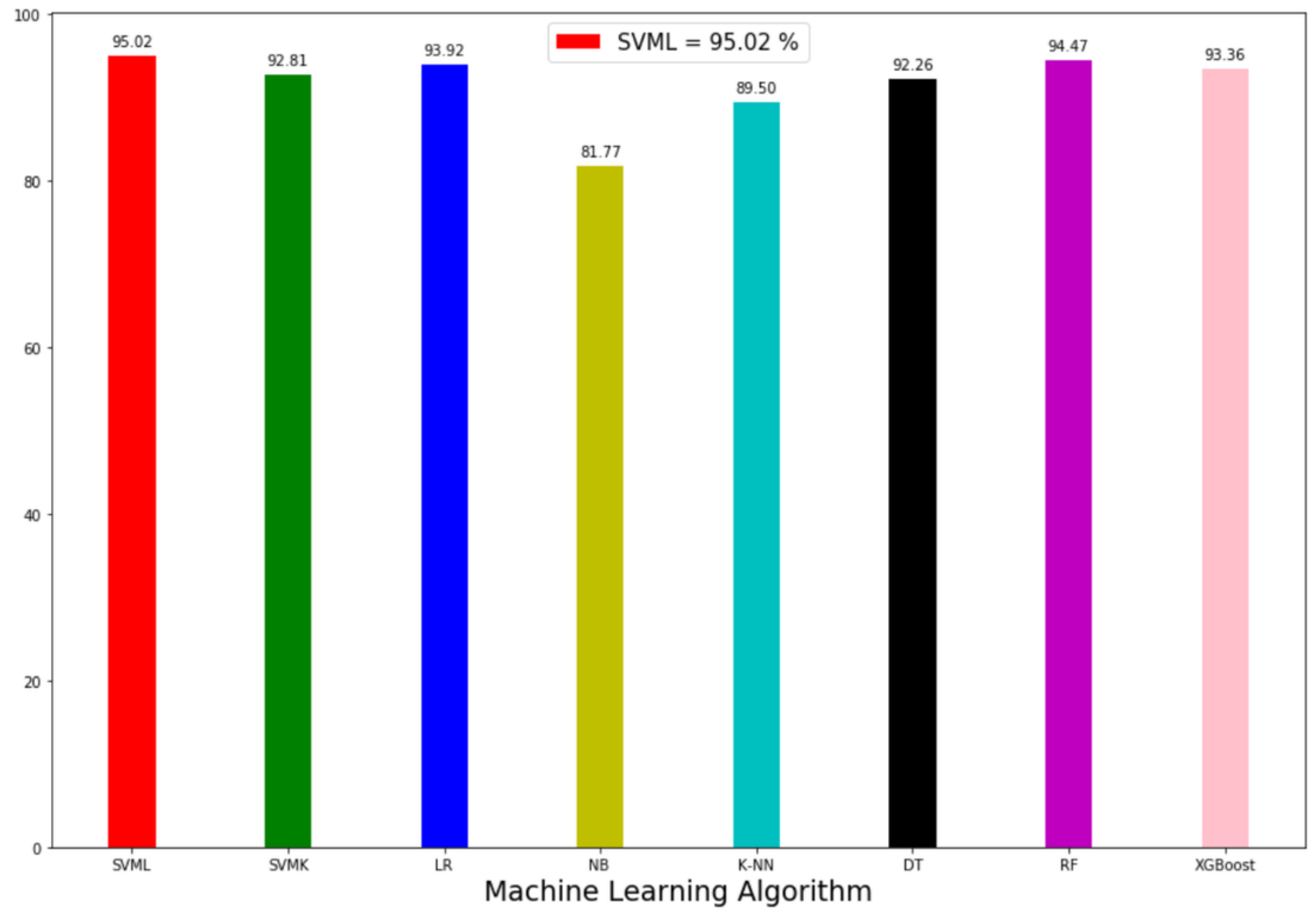




\section{Figure 7}

Figure 7. A) Model 1 comparison values (Results are colored redder as they approach the actual values and more purple as they move away). B) Confusion matrix of predicted values

Where 0 is "Hacking Tools or Malware", 1 is "Card Copying / Generating Devices", 2 is "Phishing Attack", 3 is "Creating a Fake Shopping Site", 4 is "Receiving Public Data on Social Media", 5 is "Social Engineering".
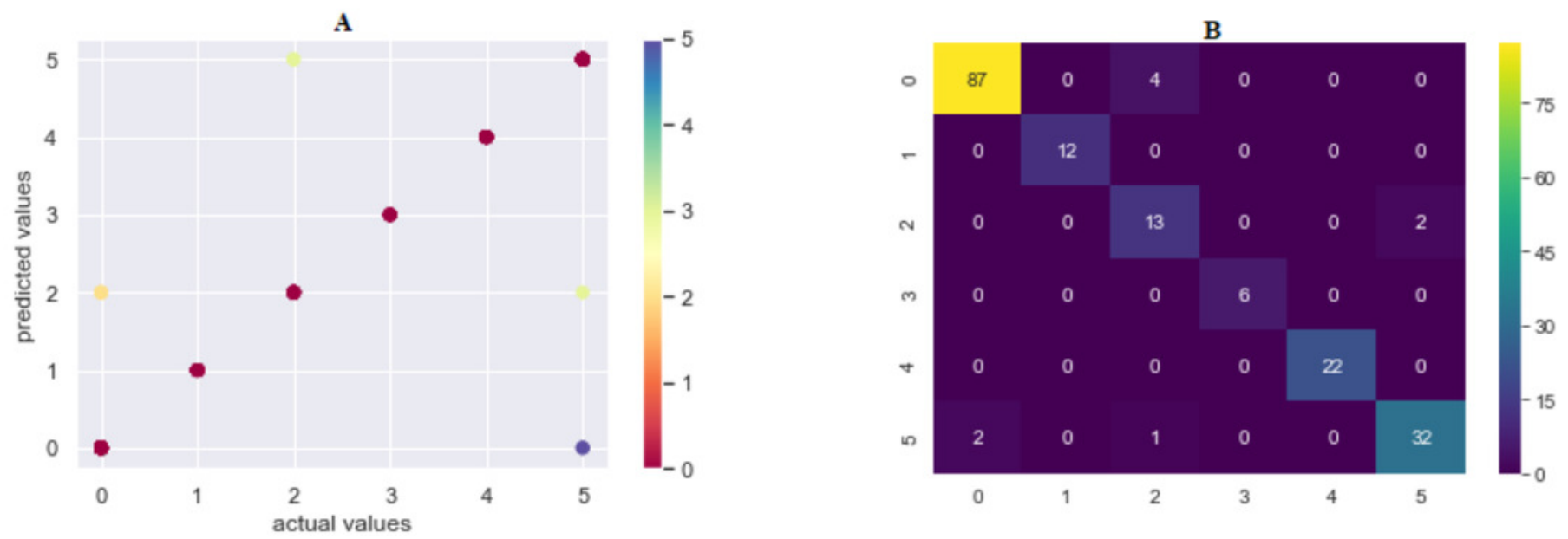
Figure 8

Figure 8. Accuracy rate of algorithms applied in perpetrator prediction method

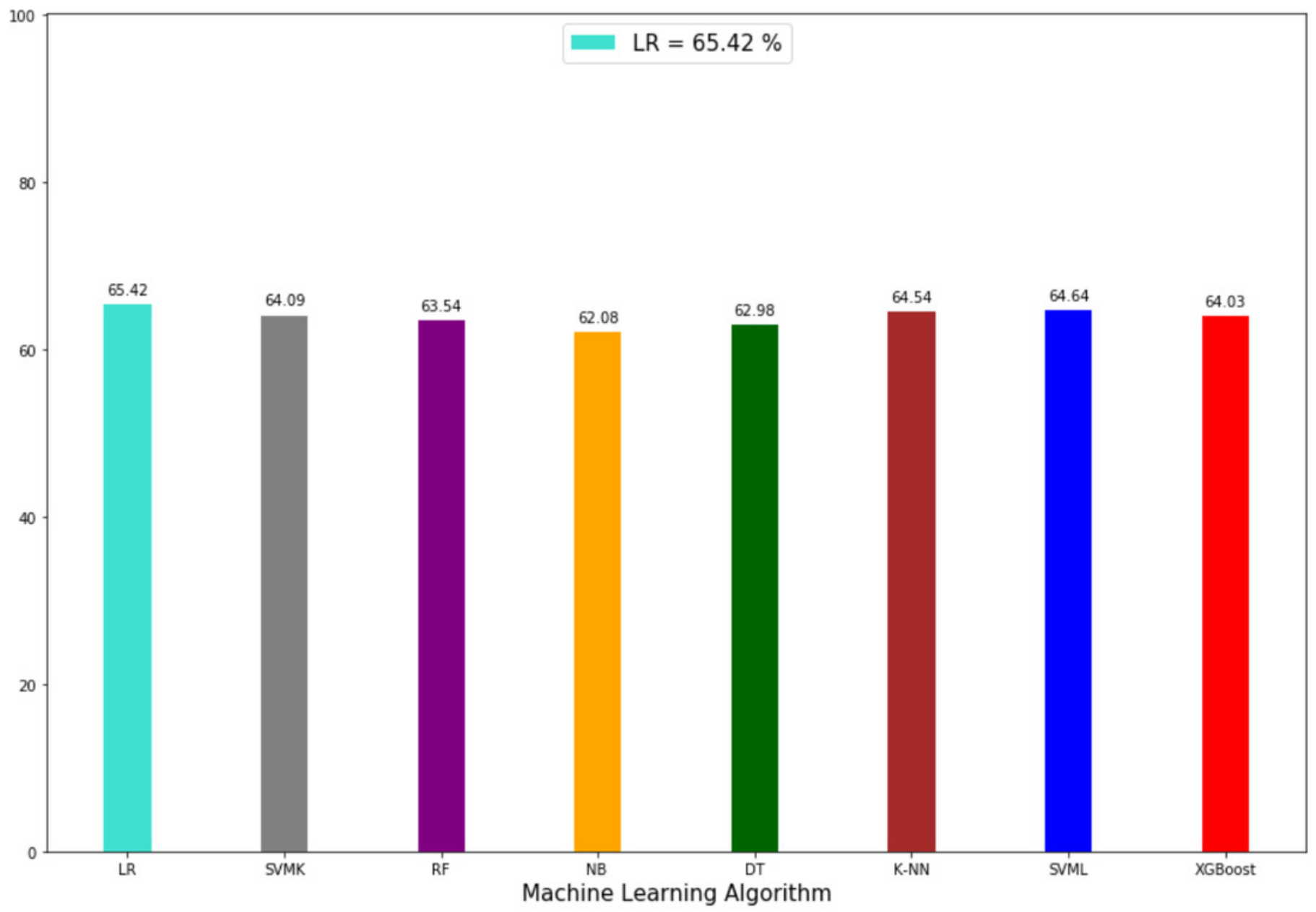




\section{Figure 9}

Figure 9. A) Model 2 comparison values (Results are colored redder as they approach the actual values and more purple as they move away). B) Confusion matrix of predicted values

Where 0 is "Perpetrator Known", 1 is "Perpetrator Unknown".
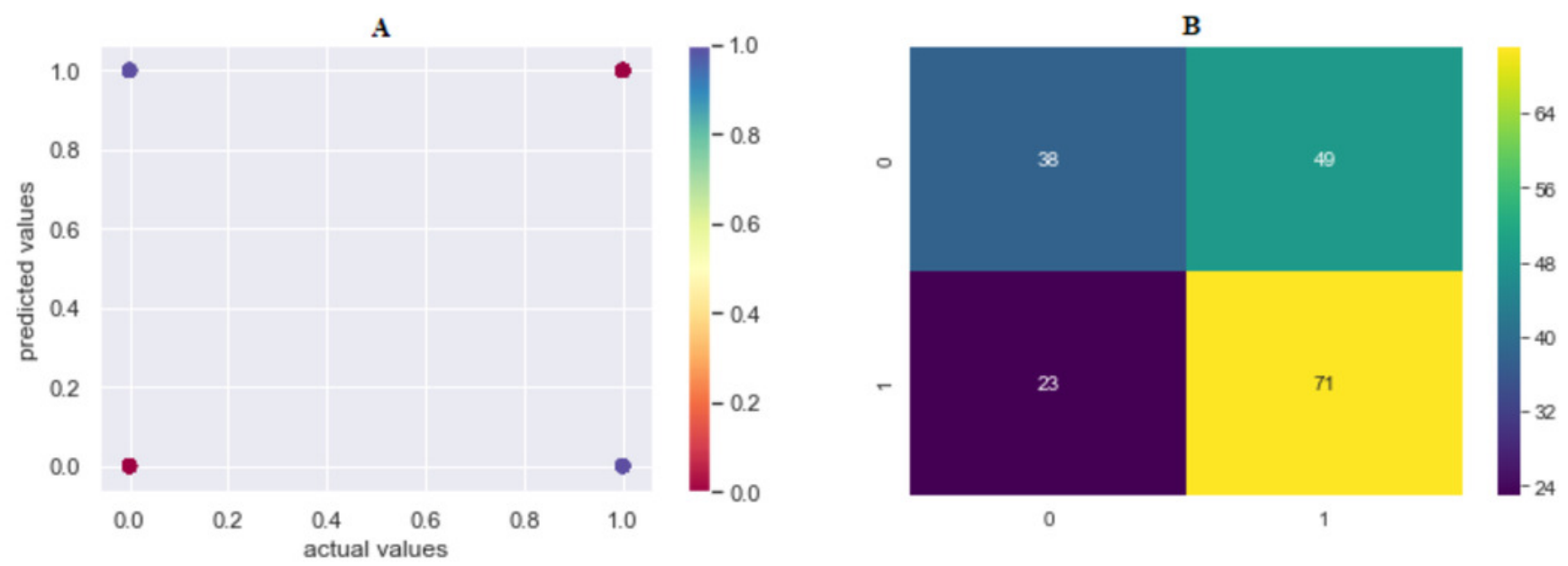